\title{
Neuroendocrine-Immune Interactions in Rheumatoid Arthritis: Mechanisms of Glucocorticoid Resistance
}

\author{
Marni N. Silverman Esther M. Sternberg \\ Section on Neuroendocrine Immunology and Behavior, National Institute of Mental Health, \\ National Institutes of Health, Rockville, Md., USA
}

\section{Key Words}

Glucocorticoids - Glucocorticoid resistance $\cdot$ Corticosteroid binding globulin - Multidrug resistance transporter . $11 \beta$-Hydroxysteroid dehydrogenase $\cdot$ Glucocorticoid receptor $\cdot$ Cytokines $\cdot$ Inflammation $\cdot$ Autoimmune disease

\begin{abstract}
Rheumatoid arthritis (RA) is characterized by chronic inflammation of the synovial membrane, leading to joint destruction. Many autoimmune diseases and disease states of chronic inflammation are accompanied by alterations in the complex interactions between the endocrine, nervous and immune systems. Glucocorticoids, an end product of the hypothalamic-pituitary-adrenal axis, are a mainstay treatment for many autoimmune diseases, including RA, because of their potent anti-inflammatory action. However, about 30\% of patients with RA fail to respond to steroid therapy. There are various mechanisms that may contribute to the development of glucocorticoid resistance in inflammatory disorders, which will be the subject of this review. In addition, glucocorticoid resistance may be a contributing factor in the development of inflammatory/autoimmune diseases themselves. Therefore, further elucidation of these mechanisms will reveal new targets for therapeutic intervention in the treatment of RA.

Copyright $\odot 2008$ S. Karger AG, Basel
\end{abstract}

\section{KARGER}

Fax +41613061234 E-Mail karger@karger.ch www.karger.com
(C) 2008 S. Karger AG, Basel

1021-7401/08/0151-0019\$24.50/0

Accessible online at:

www.karger.com/nim

\section{Introduction}

In the 1940s, Philip Hench discovered that patients with autoimmune disorders, such as rheumatoid arthritis (RA), produced an endogenous substance under 'stressful' conditions that had anti-inflammatory/immunosuppressive properties and hence, ameliorated the symptoms of the autoimmune disease. Isolation and characterization of this endogenous compound by Edward Kendall led to the discovery of the adrenal steroid, cortisone, which along with other glucocorticoids, has become a mainstay in the treatment of autoimmune and inflammatory diseases. Of note, Hench and Kendall shared the Nobel Prize in Medicine for their discovery in 1950.

Although the immunomodulatory effects of glucocorticoids initially were believed to be mediated by pharmacological rather than physiological concentrations, seminal work by Hugo Besedovsky and colleagues in the 1970s and 1980s substantiated a physiological role for glucocorticoids in regulating immune responses. Besedovsky and del Rey [1] were also one of the first to demonstrate that immune system activity could influence the release of glucocorticoids. Since then, many others have provided evidence for the bidirectional communication between the neuroendocrine and immune systems $[2,3]$. Today, in contrast to the traditional view of glucocorticoids as immunosuppressive hormones, they are more accurately

Esther M. Sternberg, MD

Integrative Neural Immune Program

Section on Neuroendocrine Immunology and Behavior

5625 Fishers Lane (MSC-9401), Rockville, MD 20852 (USA)

Tel. +1 3014022773 or 496 9255, Fax +1 301496 6095, E-Mail sternbee@mail.nih.gov 
conceptualized as immunomodulatory hormones that can stimulate as well as suppress immune function, depending on glucocorticoid concentration, the type of immune response, the immune compartment and the cell type involved [4]. Once glucocorticoids are released into the general circulation, maintenance of appropriate glucocorticoid activity is accomplished by local tissue regulation of glucocorticoid availability and action by factors such as corticosteroid binding globulin (CBG), the multidrug resistance transporter (MDR), 11 $\beta$-hydroxysteroid dehydrogenase (11 $\beta$-HSD), and ultimately, the glucocorticoid receptor (GR). Altered expression and/or function of these factors have been found in RA and have become the subject of interest for the development of new therapeutic interventions.

\section{Impaired HPA Axis Activity and Other Stress Systems in RA}

Conditions of chronic inflammation are often associated with impaired anti-inflammatory stress response systems. In addition to absolute plasma levels of stress hormones (as exemplified below), it is important to study hormone levels in relation to inflammation or steroid hormone shifts, which can indicate preferential production of one hormone over another and influence the progression of chronic inflammatory diseases [5]. In RA, alterations in neuroendocrine function include inadequate ACTH and cortisol secretion (impaired HPA axis function), an increased sympathetic tone at rest but an inadequate response during stress, functional loss of synovial sympathetic nerve fibers concomitant with the presence of proinflammatory sensory fibers, a local beta-to-alpha adrenergic receptor shift and local uncoupling of cortisol and norepinephrine. In addition, a decrease in adrenal androgen production, such as DHEAS, DHEA and androstenedione, has been reported with a preference for cortisol production (although insufficient in relation to sustained inflammation). Taken together, these alterations in stress response systems lead to insufficient regulatory/anti-inflammatory responses to keep inflammation in check and may contribute to the pathology characteristic of RA [6].

Normal plasma levels of ACTH and cortisol in the presence of systemic inflammation is indicative of an inadequate HPA axis response to systemic inflammation. Interestingly, the circadian rhythm of cortisol in RA patients, whose disease activity is relatively low to moderate, is similar to that found in healthy controls $[7,8]$, whereas a loss of circadian rhythm, as indicated by a flattened cortisol curve, has been observed in RA patients when the disease is very active [8]. Early morning peaks in plasma proinflammatory cytokine levels (e.g., TNF- $\alpha$, IL-6) are shifted a couple of hours later (to around 57 a.m.) and are of greater amplitude and longer duration in RA patients versus controls. These circadian changes, despite the similarity of the circadian curves for serum cortisol (in amplitude and shape), also indicate inadequate cortisol secretion in relation to inflammation in RA. Elevated proinflammatory cytokines probably account for the increased morning stiffness (due to edema) and pain that are usually experienced by RA patients.

A defective HPA axis has also been associated with susceptibility to autoimmune/inflammatory diseases in several animal models. In regard to RA, the neuroendocrine differences observed between Lewis $(\mathrm{LEW} / \mathrm{N})$ and Fischer $(\mathrm{F} 244 / \mathrm{N})$ rat strains are a prime example. Lewis rats are highly susceptible, whereas Fischer rats are relatively resistant, to the development of a wide range of autoimmune diseases in response to a variety of proinflammatory/antigenic stimuli. Injection of group A streptococcal cell wall peptidoglycan polysaccharide (which mimics human RA) into inflammatory-susceptible Lewis rats produces a blunted HPA axis response (ACTH and corticosterone) compared to the exaggerated HPA axis response observed in inflammatory-resistant Fischer rats. Moreover, the replacement or removal of glucocorticoids in Lewis and Fischer rats, respectively, reverses their susceptibility to streptococcal cell wall-induced arthritis [9]. Dysfunctional HPA axis activity in Lewis rats has been shown to be due to the altered expression of multiple factors that regulate the HPA axis, including hypothalamic corticotrophin-releasing hormone, pituitary proopiomelanocortin, CBG and GR [10]. Local factors regulating glucocorticoid bioavailability and actions are discussed below.

\section{Local Factors Regulating Glucocorticoid Bioavailability and Action}

\section{Factors Regulating Glucocorticoid Bioavailability}

While circulating levels of glucocorticoid hormones are relevant to steroid action, at the cellular level, activity of glucocorticoids is determined by local factors that regulate the access of free hormone to its receptor. Such factors include CBG, the MDR and $11 \beta-H S D$ (fig. 1). All of the above have been shown to be altered under conditions of immune activation. Proinflammatory cytokines tend 
Fig. 1. Local factors regulating glucocorticoid bioavailability and action: (1) CBG, (2) MDR pump, (3) $11 \beta-H S D$, (4) GR $(=\mathrm{GR} \alpha)$ nuclear translocation, (5) GR interaction with other transcription factors [AP-1 (jun/fos), NF-кB] or MAPK, and (6) ratio of GR $\alpha: G R \beta$ isoform expression. HSP $=$ Heat shock protein. [Reprinted with permission from Silverman et al.]

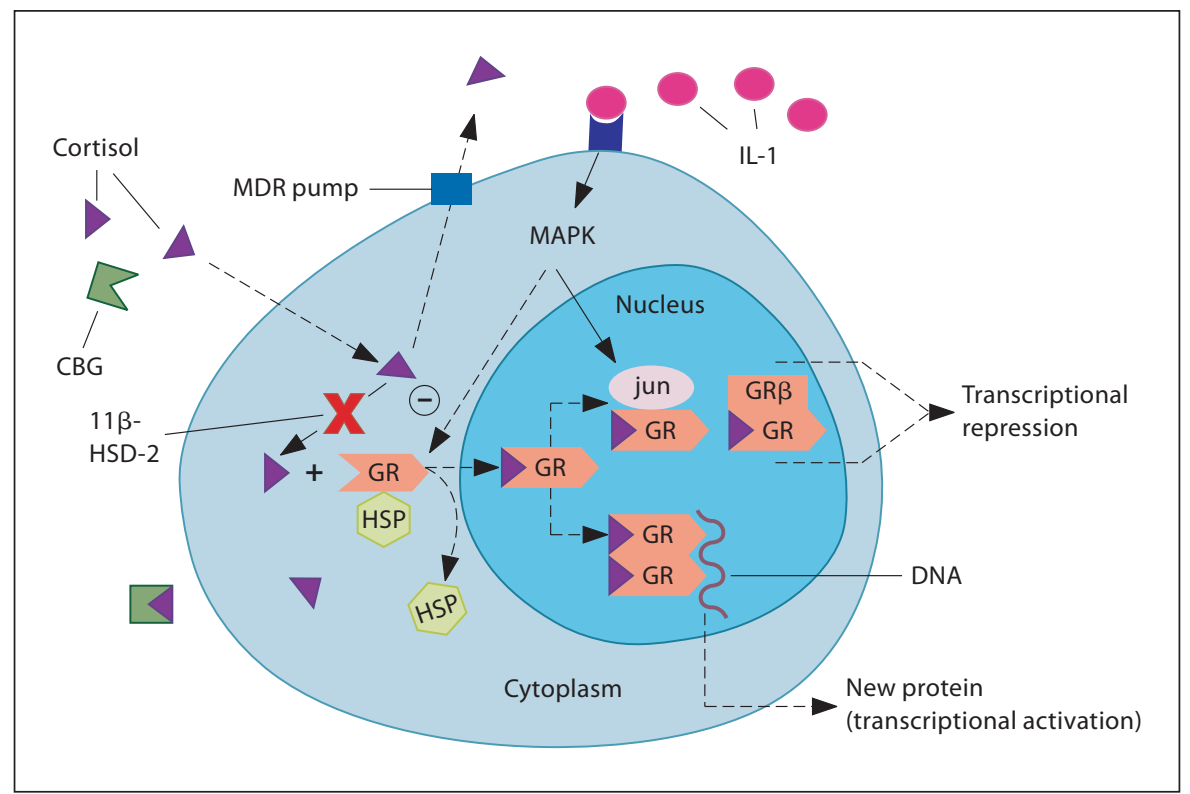

to lower CBG levels, decrease MDR expression and/or function, and increase $11 \beta-H S D-1$ expression and reductase activity (and decrease 11 $\beta$-HSD-2 expression/activity), thereby favoring an increase in glucocorticoid bioavailability. However, the opposite trend in each of these factors, which would favor a decrease in glucocorticoid bioavailability, may lead to an increased susceptibility to the development of autoimmune/inflammatory diseases.

\section{Corticosteroid Binding Globulin}

Only free or unbound glucocorticoids are capable of diffusing across the plasma membrane and activating the GR. Over $90 \%$ of circulating glucocorticoids are bound to CBG [11]. Therefore, the relative concentration of CBG is an important determinant of 'free' and available glucocorticoids. For example, decreases in the circulating level of CBG have been associated with evidence of occupation/activation of GR in the spleen of stressed rats [12]. Likewise, several studies have shown that in response to endotoxin administration in rats [13] and in a murine model of systemic lupus erythematosus [14], reduced CBG levels are observed. In addition, a decrease in plasma CBG-binding capacity has been reported in human septic shock and trauma [15-17]. In numerous studies, IL- 6 has been shown to be a negative regulator of CBG production, and hence a determinant of cortisol bioavailability $[16,18]$. In contrast, two studies examining plasma CBG during viral infection detected no change in CBG levels in infected subjects compared to controls $[19,20]$. It is important to note that even if a change in plasma CBG levels is not detected, local changes in the concentration and/or affinity of CBG during inflammation (for instance, within the microenvironment of the various lymphoid compartments or inflamed tissue) remain a consideration. In some cases, discrepancies exist between the concentration of free glucocorticoid levels in the plasma versus locally inflamed tissue, such as in RA patients who exhibit a greater percentage of bound corticosteroids in the synovial fluid relative to that found in plasma [21]. This observation demonstrates that the synovial membrane plays an important role in the local bioavailability of glucocorticoids in patients with RA.

\section{Multidrug Resistance P-Glycoprotein}

Multidrug resistance P-glycoprotein is an ATP-dependent multidrug efflux pump that decreases intracellular concentrations of potentially toxic chemicals (drugs and hormones). It is expressed in both human and rodent tissues, including the adrenal gland, kidney, liver, colon, small intestine, and brain and testis capillary endothelial cells [22]. The MDR pump at the blood-brain barrier, in both mice and humans, transports cortisol and the synthetic glucocorticoid dexamethasone, but not corticosterone, out of endothelial cells lining the brain [23]. In vitro studies have indicated that cytokines, such as IL-1, IL-6 and TNF- $\alpha$, decrease MDR expression and/or function 
in rodent hepatocytes [24, 25], human colon carcinoma cells [26] and human brain endothelial cells [27]. Moreover, rodents treated with LPS or turpentine exhibit reduced hepatic [24, 28-30], intestinal [31] and brain [28] MDR expression/activity. In contrast, humans with autoimmune diseases, such as RA $[32,33]$, colitis/Crohn's disease $[34,35]$ and lupus $[36,37]$, tend to exhibit high lymphocytic MDR expression and/or activity, which positively correlate with disease activity in some cases. However, this increased MDR expression may be secondary to treatment with high-dose glucocorticoids $[35,38]$. Increased MDR expression has been found to be more prominent in a subpopulation of colitis [39] and RA [33, 40] patients who are resistant to steroid (or disease-modifying antirheumatic drugs) therapy and may be an underlying cause of their refractory response. Therefore, evaluation of MDR expression/activity may allow prediction of the efficacy of specific drug treatments. In addition, the use of MDR inhibitors (e.g., verapamil, cyclosporin A) may help to overcome treatment resistance or to improve incomplete responses in some RA patients, as has been shown in the case of chemotherapeutic agents [41]. Combined therapy with glucocorticoids and verapamil in a small group of lupus patients was shown to reduce MDR expression [36]; however, the clinical usefulness of this approach remains to be established.

Greater MDR function in immune cells may reduce glucocorticoid availability, thereby enhancing the synthesis/release of proinflammatory cytokines and exacerbating inflammatory responses. One possible reason for the discrepancy between the in vitro cytokine/animal studies and studies in humans with autoimmune disorders may be the differential effects of acute versus chronic inflammation on MDR expression. During acute inflammation, cytokines may downregulate MDR expression and increase local glucocorticoid concentrations, thereby limiting local inflammation and further cytokine release. In contrast, an upregulation of MDR expression may develop as a compensatory mechanism during chronic inflammatory conditions, and hence predispose humans toward autoimmune disease. In support of this contention, higher levels of peripheral blood mononuclear cell (PBMC) TNF- $\alpha$ mRNA were reported in RA patients exhibiting greater lymphocytic MDR activity, where reduced amounts of cortisol would be able to act intracellularly to inhibit proinflammatory responses [33]. Both high MDR activity and TNF- $\alpha$ levels were associated with poor outcome in RA. Another possible consideration regarding discrepant results is that changes in MDR expression/function may be cell type specific (e.g.,
PBMCs vs. synovial cells). Indeed, synovial cells express MDR; however, it may be an atypical MDR phenotype [42].

$11 \beta$-Hydroxysteroid Dehydrogenase

Another factor regulating the access of glucocorticoids to their receptors in target cells and tissues is $11 \beta$ HSD. There are two isoforms of this enzyme, type 1 and type 2 . Whereas $11 \beta-H S D-1$ is a reversible oxidoreductase, $11 \beta-H S D-2$ only exhibits oxidative or dehydrogenase activity [43]. 11ß-HSD-2 breaks down naturally occurring glucocorticoids (but not synthetic glucocorticoids) as they enter the cell, leaving the hormones in the form of inactive metabolites (i.e., cortisol to cortisone in humans; corticosterone to 11-dehydrocorticosterone in rodents). Significant differences in $11 \beta-H S D-2$ activity have been found among immune compartments, and there is a direct correlation between $11 \beta-H S D-2$ activity and the preferential production of Th1 versus Th2 cytokines by $\mathrm{T}$ cells residing in particular lymphoid organs [44]. Inhibition of $11 \beta$-HSD-2 activity (which would enhance the available amount of hormone to bind to GR) leads to reduced Th1 responses and enhanced Th2 cytokine production by activated T cells [44].

Recent studies suggest that the bidirectional $11 \beta$ HSD-1 prefers the reductase direction unless cells are disrupted [43]. Therefore, in intact tissues, 11ß-HSD-1 reactivates the inactive 11-keto glucocorticoids (corticosterone/11-dehydro-corticosterone) into their active 11hydroxy glucocorticoid form (cortisol/corticosterone). Proinflammatory cytokines, such as TNF- $\alpha$ and IL-1 $\beta$, have been shown to upregulate 11 $\beta$-HSD-1 and/or downregulate $11 \beta-H S D-2$ expression/activity in numerous cell types, including rat glomerular cells [45], human adipose stromal cells [46], and more related to RA, human bone cells, such as osteoblasts [47], human fibroblasts [48] and human and mouse vascular smooth muscle cells [49]. Inflamed colon specimens (in rats and humans) also exhibit elevated $11 \beta-H S D-1$ and reduced $11 \beta-H S D-2$ expression [50], thereby favoring the formation of active glucocorticoids and counterbalancing the proinflammatory effect of cytokines.

In immune cells, $11 \beta-H S D-1$ is induced during the maturation of antigen-presenting cells, such as human macrophages [51] and murine dendritic cells [52]. It also has been shown to play a role in promoting macrophage phagocytosis of apoptotic leukocytes [53]. Morevover, $11 \beta-H S D-1$ mRNA, protein, and (reductase) activity are expressed in murine lymphocytes, where activation of CD4+ T cells into Th1 or Th2 cells increases 11ß-HSD-1 
activity [52]. In this case, the presence of greater levels of active glucocorticoids would reduce proinflammatory cytokine synthesis in Th1 cells and increase anti-inflammatory cy tokine synthesis in Th2 cells. Therefore, changes in the relative activity of $11 \beta$-HSD in immune tissues during inflammation may influence the relative impact of glucocorticoids on immune responses. Thus, the microenvironment of the various immune compartments is a potentially important site for intracrine regulation of neuroendocrine-immune interactions.

Reduced capacity for local reactivation of cortisone to cortisol has been observed in RA synovial cells, as evidenced by a greater ratio of $11 \beta-H S D-2: 11 \beta-H S D-1$-positive macrophages in the synovial tissue (compared to osteoarthritis synovium) [54]. This may be due to the local loss of catecholaminergic activity (loss of sympathetic nerve fibers and $\beta$-adrenergic receptor density on RA leukocytes) that would usually inhibit the inactivation of glucocorticoids. In addition, $11 \beta$-HSD- 2 was shown to be the second most overexpressed gene in RA and $11 \beta$-HSD2 protein levels correlated with inflammation scores [55]. Moreover, cortisone-induced inhibition of IL-6 in synovial fibroblasts has been shown to be dependent on $11 \beta$ HSD-1 activity [48] and synovial macrophages from RA patients exhibit a reduced ability of the anti-inflammatory cytokine, IL-10, to induce $11 \beta-H S D-1$ mRNA expression [56]. This defective reactivation of cortisone may be an important factor in the perpetuation of inflammation in patients with RA. The therapeutic value of $11 \beta$ HSD-2 inhibitors has not been evaluated in RA, but may serve as another target of interest.

\section{The Glucocorticoid Receptor}

The ultimate effect of glucocorticoids on immune system regulation occurs at the level of the GR. Upon glucocorticoid binding to cytosolic GRs, a conformational change in GR causes heat-shock protein 90 (hsp90) and other ancillary proteins to dissociate from the receptor, and the ligand-bound receptor then translocates into the nucleus. Here, the glucocorticoid/GR complex acts as a transcription factor that regulates gene transcription through binding to glucocorticoid response elements (GREs) in the promoter regions of genes (requires GR dimerization) or through protein-protein interactions with other transcription factors (e.g., NF- $\mathrm{\kappa B}$ and AP-1; does not require GR dimerization). A tissue's sensitivity to glucocorticoid activity can be influenced by a change in (1) GR number or affinity or (2) GR function, including its ability for nuclear translocation, its interaction with other signal transduction pathways and the expression of particular GR isoforms (fig. 1). Proinflammatory cytokines have been shown to impact a number of these factors.

\section{GR Number and Affinity}

There is a large body of data on the impact of cy tokines on GR number [57]. However, the results are split into those studies that report an increase in GR number following cytokine administration and those that report a decrease. The discrepancy in results appears to depend on how the receptors were measured. Studies using wholecell assay binding techniques tend to find an increase in cytokine-induced GR expression, while those using cytosolic receptor binding techniques tend to find a decrease. Few studies have documented changes in receptor affinity. Sher et al. [58] report that lymphocytes (T cells) simultaneously exposed to Th1 (IL-2) and Th2 (IL-4) cytokines (simulating the conditions of steroid-resistant asthma) exhibit a reduced affinity of GR for glucocorticoids. GRs on synovial fluid cells and PBMCs (but not synovial tissue cells) from RA patients have also been shown to exhibit reduced binding affinity [59]. However, no differences in GR binding affinity in PBMCs from RA patients compared to healthy controls have also been reported [60].

The GR number expressed in PBMCs of RA patients may be one factor in assessing glucocorticoid sensitivity and predicting which patients will respond to lower doses of steroid (e.g., prednisone) treatment and, therefore, avoid the unwanted side effects of higher doses. However, studies investigating GR expression in RA patients have given rise to contradictory results. Early diagnosed, untreated female (but not male) RA patients [61] and those with active disease of longer duration (off glucocorticoid therapy for at least 6 months) [60] exhibited reduced GR density in PBMCs compared to healthy controls, but GR density was not correlated with disease activity, suggesting that differential GR expression may not be involved in the pathogenesis of RA. Other studies have shown diminished GR numbers in PBMCs of glucocorticoid-treated patients, while those of untreated RA patients exhibited upregulated GR expression [62, 63], indicating that whether or not RA patients are undergoing drug therapy or are treatment naive can influence the level of GR expression. Interestingly, when measuring mRNA rather than protein, GR $\alpha$ mRNA expression in PBMCs was negatively correlated with disease activity [64]. Discrepant results may be due to the different sensitivities in change of expression levels between mRNA and protein. 
Reduced PBMC GR density has not been associated with functional glucocorticoid resistance in the sense that proliferation and cytokine release of lymphocytes of RA patients and healthy controls were inhibited by glucocorticoids to the same extent [65]. On the other hand, when subpopulations of glucocorticoid-resistant versus glucocorticoid-sensitive RA patients are selected, differences in PBMC proliferation can be detected between the two groups. Inhibition of PBMC proliferation after steroid treatment was significantly lower in a glucocorticoid-resistant as compared to a glucocorticoid-sensitive group [66]. Moreover, a positive correlation has been shown between glucocorticoid-induced inhibition of PBMC proliferation and the clinical outcome of glucocorticoid treatment in RA [67]. Therefore, the measurement of steroid sensitivity of peripheral lymphocytes (not necessarily reflected by GR number) may be a useful tool in predicting the therapeutic efficacy of glucocorticoids in RA patients.

Although all nucleated cells in humans have GRs, in $\mathrm{RA}$, it is important to consider possible abnormalities in GR expression/function in the synovium, and hence glucocorticoid sensitivity at the site of inflammation. Indeed, GRs are expressed by multiple cell types in synovial tissue, including lymphocytes, fibroblasts, endothelial cells and smooth muscle cells in the sublining layer [68], suggesting that glucocorticoids directly target the synovium. GR expression on subsynovial fibroblastic cells of RA patients pretreated with glucocorticoids was significantly lower compared to patients who had not received GC treatment; however, less suppression of GR expression was observed in patients on low-dose GC treatment [68], supporting the majority of findings regarding GR expression in PBMCs of RA patients. Further investigation is needed to determine how synovial GR expression may relate to disease activity.

\section{GR Function}

Several autoimmune/inflammatory disorders have been associated with impaired GR function, possibly contributing to the excessive inflammation characteristic of these illnesses [69]. Proinflammatory cytokines (i.e., TNF- $\alpha$, IL-1, and IL-6) and cytokines that mediate lymphocyte growth and differentiation (i.e., IL-2, IL-4) have been found to inhibit GR function [57].

Although the mechanism by which cytokines inhibit GR is unknown, several possibilities have been considered. First, cytokines may influence GR function through their effects on GR translocation from the cytoplasm into the nucleus. For example, TNF- $\alpha$ and IL-1 have been shown to block dexamethasone-induced GR nuclear translocation [70, 71]. Another possible mechanism by which cytokines may influence GR is through cross talk among signal transduction pathways. For example, downstream in the IL-1 and TNF- $\alpha$ signal transduction pathways are the transcription factors NF- $\kappa \mathrm{B}$ and AP-1 (which consists of jun and fos proteins). GR and NF- $\mathrm{B} /$ AP-1 have been shown to mutually antagonize each other's transcriptional activity through multiple mechanisms [72-74]. In addition, IL-1 and TNF- $\alpha$ activate mitogen-activated protein kinase (MAPK) signaling pathways [i.e., p38 MAPK and jun N-terminal kinase (JNK)], which have been shown to be inhibitory to GR function [75-78]. It has recently been shown that a major mechanism by which glucocorticoids exert their inhibitory action on MAPK pathways, and therefore inflammation, is by the upregulation of the MAPK phosphatase, MKP-1 [79]. Other cytokines, such as IL- 6 , IFN- $\alpha / \beta$, IFN- $\gamma$, IL12 , IL-2, and IL-4, induce janus kinase (JAK)/signal transduction and activator of transcription (STAT) signaling pathways, and STAT proteins have been found to reciprocally influence GR activity by direct protein-protein interactions $[72,74,80]$. Indeed, immune-related transcription factors, such as NF- $\kappa \mathrm{B}, \mathrm{AP}-1, \mathrm{MAPKs}$ and STATs, are elevated in PBMCs and/or synovial tissue of RA patients [81-85], and may serve as another mechanism by which cytokines can confer a glucocorticoid-resistant state. On the other hand, a deficit in inhibitory signaling molecules, such as MKP-1, may also contribute to reduced glucocorticoid sensitivity in inflammatory/ autoimmune diseases [79]. Interestingly, elevated levels of macrophage inhibitory factor, a proinflammatory cytokine that directly counteracts the immunosuppressive actions of glucocorticoids, have been demonstrated in RA and other chronic inflammatory diseases, and has been shown to exert its antiglucocorticoid effects through MKP-1 inhibition [86, 87]. Therefore, therapeutic interventions aimed at antagonizing inflammatory signaling pathways may be another way to increase glucocorticoid sensitivity.

Finally, cytokines may affect GR function by altering the ratio of $G R \alpha: G R \beta$ isoform expression. Alternative splicing of the human GR primary transcript produces multiple isoforms [88]. The two that have received the most attention are GR $\alpha$, the classical transcriptionally active isoform, and GR $\beta$, which may negatively regulate GR $\alpha$ activity. The GR $\alpha$ isoform binds hormone and activates glucocorticoid-responsive genes, while the GR $\beta$ isoform fails to bind hormone and activate glucocorticoid-responsive genes and attenuates the trans-activation 
of the hormone-bound GR $\alpha$ isoform [89]. These findings suggest that when GR $\beta$ is present in excess in various tissues (reduced GR $\alpha: G R \beta$ ratio), it can act as a dominant negative inhibitor of GR $\alpha$ activity. In fact, Webster et al. [90] have shown that IL-1 and TNF- $\alpha$ lead to the selective accumulation of GR $\beta$ protein in cells of lymphoid origin and the development of a glucocorticoid-resistant state. Interestingly, glucocorticoid sensitivity in different immune cell types has been associated with varied degrees of GR $\beta$ expression $[91,92]$. Moreover, increases in GR $\beta$ levels have been found in immune cells of patients with glucocorticoid-resistant asthma [93, 94], colitis/Crohn's disease [95, 96] and RA [97].

Derijk et al. [98] were the first to demonstrate that a polymorphism in the human GR $\beta$ gene, which increases its mRNA stability, is associated with RA. Other polymorphisms of the GR have also been associated with RA, whereby those that confer an increased glucocorticoid sensitivity (i.e., N363S and BclI) are associated with a decreased susceptibility to develop RA and those related to reduced glucocorticoid sensitivity (i.e., ER22/23EK and GR $\beta-A 3669$ G) are associated with an enhanced predisposition to develop RA [van Oosten et al., unpubl. data]. However, other studies have failed to find an association with GR polymorphisms and RA susceptibility $[99,100]$. Screening for GR polymorphisms in RA patients may also aid in the identification of those who will benefit the most from glucocorticoid treatment [for a review of common GR polymorphisms and their associations with disease, see 101, 102]. Alternative translation initiation of $\mathrm{GR} \alpha$ mRNA can also lead to the expression of GR isoforms with different transcriptional activity [103]. The unique transcriptional activities and distinct tissue-specific distribution patterns of $\mathrm{GR} \alpha$ isoforms could provide a novel mechanism for tissue-specific glucocorticoid responses.
Table 1. Molecular mechanisms of glucocorticoid resistance

\begin{tabular}{lll}
\hline$\uparrow$ CBG & $\rightarrow$ & $\downarrow$ free GCs \\
$\uparrow$ MDR Pgp expression & $\rightarrow$ & $\downarrow$ intracellular GCs \\
$\downarrow 11 \beta-H S D-1 / \uparrow 11 \beta-H S D-2$ & $\rightarrow$ & $\downarrow$ active GCs \\
$\downarrow$ GR affinity for GCs & $\rightarrow$ & $\downarrow$ GR function \\
$\downarrow$ GR translocation into nucleus & $\rightarrow$ & $\downarrow$ GR function \\
$\uparrow$ Expression of AP-1 and NF- $\mathrm{B}$ & $\rightarrow$ & $\downarrow$ GR function \\
$\uparrow$ Expression of MAPKs (p38, JNK) & $\rightarrow$ & $\downarrow$ GR function \\
$\uparrow$ Expression of GR $\beta$ isoform & $\rightarrow$ & $\downarrow$ GR function \\
\hline
\end{tabular}

MDR Pgp $=$ Multidrug resistance P-glycoprotein.

\section{Conclusion}

A variety of factors have been shown to regulate GC availability or bioactivity. A change in any of them towards reduced glucocorticoid function can lead to the development of glucocorticoid resistance (table 1). Should this occur during chronic inflammation, patients would be expected to be more susceptible to the deleterious, tissue-damaging effects of an overproduction of proinflammatory cytokines, which may increase vulnerability to the development of autoimmune disease. Further investigation is required to assess the safety and efficacy of new therapeutic strategies, including inhibitors of the multidrug resistance P-glycoprotein, $11 \beta-H S D-2$ and downstream inflammatory signaling molecules (e.g., AP-1, NF-кB, STAT, MAPKs), which may help to reverse a state of glucocorticoid resistance.

\section{Acknowledgments}

The authors would like to thank the National Institute of Mental Health for their continued support and the Prince of Wales Foundation funded NCCAM Director's Fellowship that has been granted to MNS.

\section{References}

1 Besedovsky HO, del Rey A: Immune-neuroendocrine interactions: facts and hypotheses. Endocr Rev 1996;17:64-102.

2 Silverman MN, Pearce BD, Biron CA, Miller AH: Immune modulation of the hypothalamic-pituitary-adrenal (HPA) axis during viral infection. Viral Immunol 2005; 18:4178.
3 Sternberg EM: Neural regulation of innate immunity: a coordinated nonspecific host response to pathogens. Nat Rev Immunol 2006;6:318-328
4 McEwen BS, Biron CA, Brunson KW, Bulloch K, Chambers WH, Dhabhar FS, Goldfarb RH, Kitson RP, Miller AH, Spencer RL, Weiss JM: The role of adrenocorticoids as modulators of immune function in health and disease: neural, endocrine and immune interactions. Brain Res Brain Res Rev 1997; 23:79-133. 
5 Straub RH, Cutolo M: Involvement of the hypothalamic-pituitary-adrenal/gonadal axis and the peripheral nervous system in rheumatoid arthritis: viewpoint based on a systemic pathogenetic role. Arthritis Rheum 2001;44:493-507.

6 Straub RH, Dhabhar FS, Bijlsma JW, Cutolo M: How psychological stress via hormones and nerve fibers may exacerbate rheumatoid arthritis. Arthritis Rheum 2005;52:16-26.

7 Crofford LJ, Kalogeras KT, Mastorakos G, Magiakou MA, Wells J, Kanik KS, Gold PW, Chrousos GP, Wilder RL: Circadian relationships between interleukin (IL)-6 and hypothalamic-pituitary-adrenal axis hormones: failure of IL-6 to cause sustained hypercortisolism in patients with early untreated rheumatoid arthritis. J Clin Endocrinol Metab 1997;82:1279-1283.

8 Straub RH, Cutolo M: Circadian rhythms in rheumatoid arthritis: implications for pathophysiology and therapeutic management. Arthritis Rheum 2007;56:399-408.

9 Sternberg EM, Hill JM, Chrousos GP, Kamilaris T, Listwak SJ, Gold PW, Wilder RL: Inflammatory mediator-induced hypothalamic-pituitary-adrenal axis activation is defective in streptococcal cell wall arthritissusceptible Lewis rats. Proc Natl Acad Sci USA 1989;86:2374-2378.

10 Eskandari F, Webster JI, Sternberg EM: Neural immune pathways and their connection to inflammatory diseases. Arthritis Res Ther 2003;5:251-265.

11 Rosner W: Plasma steroid-binding proteins. Endocrinol Metab Clin 1991;20:697-720.

12 Spencer RL, Miller AH, Moday H, McEwen BS, Blanchard RJ, Blanchard DC, Sakai RR: Chronic social stress produces reductions in available splenic type II corticosteroid receptor binding and plasma corticosteroid binding globulin levels. Psychoneuroendocrinology 1996;21:95-109.

13 Shanks N, Windle RJ, Perks P, Wood S, Ingram CD, Lightman SL: The hypothalamicpituitary-adrenal axis response to endotoxin is attenuated during lactation. J Neuroendocrinol 1999;11:857-865.

14 Shanks N, Moore PM, Perks P, Lightman SL: Alterations in hypothalamic-pituitary-adrenal function correlated with the onset of murine SLE in MRL +/+ and lpr/lpr mice. Brain Behav Immun 1999;13:348-360.

15 Beishuizen A, Thijs LG, Vermes I: Patterns of corticosteroid-binding globulin and the free cortisol index during septic shock and multitrauma. Intensive Care Med 2001;27:15841591.

16 Bernier J, Jobin N, Emptoz-Bonneton A, Pugeat MM, Garrel DR: Decreased corticosteroid-binding globulin in burn patients: relationship with interleukin-6 and fat in nutritional support. Crit Care Med 1998;26: 452-460.
17 Ho JT, Al-Musalhi H, Chapman MJ, Quach T, Thomas PD, Bagley CJ, Lewis JG, Torpy DJ: Septic shock and sepsis: a comparison of total and free plasma cortisol levels. J Clin Endocrinol Metab 2006;91:105-114.

18 Tsigos C, Kyrou I, Chrousos GP, Papanicolaou DA: Prolonged suppression of corticosteroid-binding globulin by recombinant human interleukin-6 in man. J Clin Endocrinol Metab 1998;83:3379.

19 Lambert M: Thyroid dysfunction in HIV infection. Baillieres Clin Endocrinol Metab 1994;8:825-835.

20 Miller AH, Spencer RL, Pearce BD, Pisell TL, Tanapat P, Leung JJ, Dhabhar FS, McEwen BS, Biron CA: 1996 Curt P. Richter Award. Effects of viral infection on corticosterone secretion and glucocorticoid receptor binding in immune tissues. Psychoneuroendocrinology 1997;22:455-474.

21 Feher KG, Zahumenszky Z, Feher T, Banyai B: Protein-corticosteroid interactions in peripheral plasma and synovial fluid of patients with rheumatoid arthritis and osteoarthrosis. Z Rheumatol 1980;39:176-181.

22 Chin KV, Chauhan SS, Pastan I, Gottesman MM: Regulation of mdr RNA levels in response to cytotoxic drugs in rodent cells. Cell Growth Differ 1990;1:361-365.

23 Karssen AM, Meijer OC, van der Sandt IC Lucassen PJ, de Lange EC, de Boer AG, de Kloet ER: Multidrug resistance P-glycoprotein hampers the access of cortisol but not of corticosterone to mouse and human brain. Endocrinology 2001;142:2686-2694.

24 Hartmann G, Kim H, Piquette-Miller M: Regulation of the hepatic multidrug resistance gene expression by endotoxin and inflammatory cytokines in mice. Int Immunopharmacol 2001;1:189-199.

25 Sukhai M, Yong A, Pak A, Piquette-Miller M: Decreased expression of P-glycoprotein in interleukin-1beta and interleukin- 6 treated rat hepatocytes. Inflamm Res 2001;50: 362-370.

26 Stein U, Walther W, Shoemaker RH: Modulation of mdrl expression by cytokines in human colon carcinoma cells: an approach for reversal of multidrug resistance. $\mathrm{Br} J$ Cancer 1996;74:1384-1391.

27 Mandi Y, Ocsovszki I, Szabo D, Nagy Z, Nelson J, Molnar J: Nitric oxide production and MDR expression by human brain endothelial cells. Anticancer Res 1998;18:30493052 .

28 Goralski KB, Hartmann G, Piquette-Miller M, Renton KW: Downregulation of mdrla expression in the brain and liver during CNS inflammation alters the in vivo disposition of digoxin. Br J Pharmacol 2003;139:35-48.

29 Piquette-Miller M, Pak A, Kim H, Anari R, Shahzamani A: Decreased expression and activity of P-glycoprotein in rat liver during acute inflammation. Pharm Res 1998;15: 706-711.
30 Sukhai M, Yong A, Kalitsky J, Piquette-Miller M: Inflammation and interleukin-6 mediate reductions in the hepatic expression and transcription of the mdrla and mdrlb genes. Mol Cell Biol Res Commun 2000;4: 248-256.

31 Kalitsky-Szirtes J, Shayeganpour A, Brocks DR, Piquette-Miller M: Suppression of drugmetabolizing enzymes and efflux transporters in the intestine of endotoxin-treated rats. Drug Metab Dispos 2004;32:20-27.

32 Borowski LC, Lopes RP, Gonzalez TP, Dummer LA, Chies JA, Silveira IG, Keisermann $\mathrm{M}$, Bauer ME: Is steroid resistance related to multidrug resistance-I (MDR-I) in rheumatoid arthritis? Int Immunopharmacol 2007; 7:836-844

33 Llorente L, Richaud-Patin Y, Diaz-Borjon A, Alvarado de la Barrera C, Jakez-Ocampo J, de la Fuente H, Gonzalez-Amaro R, DiazJouanen E: Multidrug resistance-1 (MDR-1) in rheumatic autoimmune disorders. I. Increased P-glycoprotein activity in lymphocytes from rheumatoid arthritis patients might influence disease outcome. Joint Bone Spine 2000;67:30-39.

34 Farrell RJ, Murphy A, Long A, Donnelly S, Cherikuri A, O’Toole D, Mahmud N, Keeling PW, Weir DG, Kelleher D: High multidrug resistance (P-glycoprotein 170) expression in inflammatory bowel disease patients who fail medical therapy. Gastroenterology 2000;118:279-288.

35 Hirano T, Onda K, Toma T, Miyaoka M, Moriyasu F, Oka K: MDR1 mRNA expressions in peripheral blood mononuclear cells of patients with ulcerative colitis in relation to glucocorticoid administration. J Clin Pharmacol 2004;44:481-486.

36 Diaz-Borjon A, Richaud-Patin Y, Alvarado de la Barrera C, Jakez-Ocampo J, Ruiz-Arguelles A, Llorente L: Multidrug resistance-1 (MDR-1) in rheumatic autoimmune disorders. II. Increased P-glycoprotein activity in lymphocytes from systemic lupus erythematosus patients might affect steroid requirements for disease control. Joint Bone Spine 2000;67:40-48.

37 Tsujimura S, Saito K, Nakayamada S, Tanaka Y: Relevance of multidrug resistance 1 and P-glycoprotein to drug resistance in patients with systemic lupus erythematosus. Histol Histopathol 2007;22:465-468.

38 Maillefert JF, Maynadie M, Tebib JG, Aho S, Walker P, Chatard C, Dulieu V, Bouvier M, Carli PM, Tavernier C: Expression of the multidrug resistance glycoprotein 170 in the peripheral blood lymphocytes of rheumatoid arthritis patients. The percentage of lymphocytes expressing glycoprotein 170 is increased in patients treated with prednisolone. Br J Rheumatol 1996;35:430-435. 
39 Sambuelli AM, Negreira SM, Gil AH, Huernos SP, Goncalves S, Toro MA, Kogan Z, Cabanne A, Camarero S, Bai JC, Lazarowski AJ: Multidrug resistance gene (MDR-1) expression in the colonic mucosa of patients with refractory ulcerative colitis. Acta Gastroenterol Latinoam 2006;36:23-32.

40 Yudoh K, Matsuno H, Nakazawa F, Yonezawa $\mathrm{T}$, Kimura $\mathrm{T}$ : Increased expression of multidrug resistance of P-glycoprotein on Th1 cells correlates with drug resistance in rheumatoid arthritis. Arthritis Rheum 1999; 42:2014-2015.

41 Richaud-Patin Y, Soto-Vega E, Jakez-Ocampo J, Llorente L: P-glycoprotein in autoimmune diseases. Autoimmun Rev 2004;3: 188-192.

42 Jorgensen C, Sun R, Rossi JF, Costes J, Richard D, Bologna C, Sany J: Expression of a multidrug resistance gene in human rheumatoid synovium. Rheumatol Int 1995; 15 : 83-86.

43 Seckl JR, Walker BR: Minireview: 11beta-hydroxysteroid dehydrogenase type 1 - a tissue-specific amplifier of glucocorticoid action. Endocrinology 2001;142:1371-1376.

44 Hennebold JD, Ryu SY, Mu HH, Galbraith A, Daynes RA: 11 beta-hydroxysteroid dehydrogenase modulation of glucocorticoid activities in lymphoid organs. Am J Physiol 1996;270:R1296-R1306.

45 Escher G, Galli I, Vishwanath BS, Frey BM, Frey FJ: Tumor necrosis factor alpha and interleukin 1beta enhance the cortisone/cortisol shuttle. J Exp Med 1997;186:189-198.

46 Tomlinson JW, Moore J, Cooper MS, Bujalska I, Shahmanesh M, Burt C, Strain A, Hewison M, Stewart PM: Regulation of expression of 11beta-hydroxysteroid dehydrogenase type 1 in adipose tissue: tissue-specific induction by cytokines. Endocrinology 2001;142:1982-1989.

47 Cooper MS, Bujalska I, Rabbitt E, Walker EA, Bland R, Sheppard MC, Hewison M, Stewart PM: Modulation of 11beta-hydroxysteroid dehydrogenase isozymes by proinflammatory cytokines in osteoblasts: an autocrine switch from glucocorticoid inactivation to activation. J Bone Miner Res 2001; 16:1037-1044

48 Hardy RS, Filer A, Cooper MS, Parsonage G, Raza K, Hardie DL, Rabbitt EH, Stewart PM, Buckley CD, Hewison M: Differential expression, function and response to inflammatory stimuli of 11beta-hydroxysteroid dehydrogenase type 1 in human fibroblasts: a mechanism for tissue-specific regulation of inflammation. Arthritis Res Ther 2006;8: R108.

49 Dover AR, Hadoke PW, Macdonald LJ, Miller E, Newby DE, Walker BR: Intravascular glucocorticoid metabolism during inflammation and injury in mice. Endocrinology 2007;148:166-172.
50 Zbankova S, Bryndova J, Leden P, Kment M, Svec A, Pacha J: 11beta-hydroxysteroid dehydrogenase 1 and 2 expression in colon from patients with ulcerative colitis. J Gastroenterol Hepatol 2007;22:1019-1023.

51 Thieringer R, Le Grand CB, Carbin L, Cai TQ, Wong B, Wright SD, Hermanowski-Vosatka A: 11 Beta-hydroxysteroid dehydrogenase type 1 is induced in human monocytes upon differentiation to macrophages. J Immunol 2001;167:30-35.

52 Zhang YT, Ding X, Daynes RA: The expression of 11 beta-hydroxysteroid dehydrogenase type I by lymphocytes provides a novel means for intracrine regulation of glucocorticoid activities. J Immunol 2005;174:879889.

53 Gilmour JS, Coutinho AE, Cailhier JF, Man TY, Clay M, Thomas G, Harris HJ, Mullins JJ, Seckl JR, Savill JS, Chapman KE: Local amplification of glucocorticoids by 11 betahydroxysteroid dehydrogenase type 1 promotes macrophage phagocytosis of apoptotic leukocytes. J Immunol 2006;176:76057611.

54 Schmidt M, Weidler C, Naumann H, Anders S, Scholmerich J, Straub RH: Reduced capacity for the reactivation of glucocorticoids in rheumatoid arthritis synovial cells: possible role of the sympathetic nervous system? Arthritis Rheum 2005;52:1711-1720.

55 Haas CS, Creighton CJ, Pi X, Maine I, Koch AE, Haines GK, Ling S, Chinnaiyan AM, Holoshitz J: Identification of genes modulated in rheumatoid arthritis using complementary DNA microarray analysis of lymphoblastoid B cell lines from diseasediscordant monozygotic twins. Arthritis Rheum 2006;54:2047-2060.

56 Antoniv TT, Ivashkiv LB: Dysregulation of interleukin-10-dependent gene expression in rheumatoid arthritis synovial macrophages. Arthritis Rheum 2006;54:27112721

57 Miller AH, Pearce BD, Ruzek MC, Biron CA: Interactions between the hypothalamic-pituitary-adrenal axis and immune system during viral infection: pathways for environmental effects on disease expression; in McEwen BS (ed): Handbook of Physiology. Section 7: The Endocrine System. New York, Oxford University Press, 2001, vol 4: Coping with the Environment: Neural and Endocrine Mechanisms, pp 425-450.

58 Sher ER, Leung DY, Surs W, Kam JC, Zieg G, Kamada AK, Szefler SJ: Steroid-resistant asthma. Cellular mechanisms contributing to inadequate response to glucocorticoid therapy. J Clin Invest 1994;93:33-39.

59 Braidman IP, Livingston K, Tomlinson IW, Jayson MI, Jasani MK: Effect of inflammatory arthritis on dexamethasone receptors in phagocytes - a possible role for plasma factors. Agents Actions 1981;11:602-604.
60 Schlaghecke R, Kornely E, Wollenhaupt J, Specker C: Glucocorticoid receptors in rheumatoid arthritis. Arthritis Rheum 1992;35: 740-744.

61 van Everdingen AA, Huisman AM, Wenting MJ, van Reesema S, Jacobs JW, Bijlsma JW: Downregulation of glucocorticoid receptors in early-diagnosed rheumatoid arthritis. Clin Exp Rheumatol 2002;20:463-468.

62 Eggert M, Kluter A, Rusch D, Schmidt KL, Dotzlaw H, Schulz M, Pabst W, Boke J, Renkawitz R, Neeck G: Expression analysis of the glucocorticoid receptor and the nuclear factor-kB subunit p50 in lymphocytes from patients with rheumatoid arthritis. J Rheumatol 2002;29:2500-2506.

63 Sanden S, Tripmacher R, Weltrich R, Rohde W, Hiepe F, Burmester GR, Buttgereit F: Glucocorticoid dose dependent downregulation of glucocorticoid receptors in patients with rheumatic diseases. J Rheumatol 2000;27: 1265-1270.

64 Onda K, Rimbara E, Hirano T, Oka K, Abe $\mathrm{H}$, Tahara K, Takanashi H, Tsuboi N, Niitsuma T, Hayashi T: Role of mRNA expression of transcription factors in glucocorticoid sensitivity of peripheral blood mononuclear cells and disease state in rheumatoid arthritis. J Rheumatol 2004;31:464-469.

65 Schlaghecke R, Beuscher D, Kornely E, Specker C: Effects of glucocorticoids in rheumatoid arthritis. Diminished glucocorticoid receptors do not result in glucocorticoid resistance. Arthritis Rheum 1994;37:11271131.

66 Sliwinska-Stanczyk P, Pazdur J, Ziolkowska M, Jaworski J, Kaminska-Tchorzewska E, Lacki JK: The effect of methylprednisolone on proliferation of PBMCs obtained from steroid-sensitive and steroid-resistant rheumatoid arthritis patients. Scand J Rheumatol 2007;36:167-171.

67 Kirkham BW, Corkill MM, Davison SC, Panayi GS: Response to glucocorticoid treatment in rheumatoid arthritis: in vitro cell mediated immune assay predicts in vivo responses. J Rheumatol 1991;18:821-825.

68 Tohyama CT, Yamakawa M, Murasawa A, Nakazono K, Ishikawa H: Localization of human glucocorticoid receptor in rheumatoid synovial tissue of the knee joint. Scand J Rheumatol 2005;34:426-432.

69 DeRijk R, Sternberg EM: Corticosteroid resistance and disease. Ann Med 1997;29:79_ 82.

70 Adcock IM, Brown CR, Barnes PI: Tumour necrosis factor alpha causes retention of activated glucocorticoid receptor within the cytoplasm of A549 cells. Biochem Biophys Res Commun 1996;225:545-550.

71 Pariante CM, Pearce BD, Pisell TL, Sanchez CI, Po C, Su C, Miller AH: The proinflammatory cytokine, interleukin-1alpha, reduces glucocorticoid receptor translocation and function. Endocrinology 1999; 140: $4359-4366$. 
72 Adcock IM, Caramori G: Cross-talk between pro-inflammatory transcription factors and glucocorticoids. Immunol Cell Biol 2001;79: 376-384.

73 De Bosscher K, Vanden Berghe W, Haegeman G: Mechanisms of anti-inflammatory action and of immunosuppression by glucocorticoids: negative interference of activated glucocorticoid receptor with transcription factors. J Neuroimmunol 2000;109:16-22.

74 Smoak KA, Cidlowski JA: Mechanisms of glucocorticoid receptor signaling during inflammation. Mech Ageing Dev 2004; 125: 697-706.

75 Irusen E, Matthews JG, Takahashi A, Barnes PJ, Chung KF, Adcock IM: p38 Mitogen-activated protein kinase-induced glucocorticoid receptor phosphorylation reduces its activity: role in steroid-insensitive asthma. J Allergy Clin Immunol 2002;109:649-657.

76 Rogatsky I, Logan SK, Garabedian MJ: Antagonism of glucocorticoid receptor transcriptional activation by the c-Jun N-terminal kinase. Proc Natl Acad Sci USA 1998;95: 2050-2055.

77 Wang X, Wu H, Lakdawala VS, Hu F, Hanson ND, Miller AH: Inhibition of Jun N-terminal kinase (JNK) enhances glucocorticoid receptor-mediated function in mouse hippocampal HT22 cells. Neuropsychopharmacology 2005;30:242-249.

78 Wang $\mathrm{X}, \mathrm{Wu} \mathrm{H}$, Miller $\mathrm{AH}$ : Interleukin 1alpha (IL-1alpha) induced activation of p38 mitogen-activated protein kinase inhibits glucocorticoid receptor function. Mol Psychiatry 2004;9:65-75.

79 Clark AR: MAP kinase phosphatase 1: a novel mediator of biological effects of glucocorticoids? J Endocrinol 2003;178:5-12.

80 Shuai K: Modulation of STAT signaling by STAT-interacting proteins. Oncogene 2000; 19:2638-2644.

81 Chikanza IC, Kozaci DL: Corticosteroid resistance in rheumatoid arthritis: molecular and cellular perspectives. Rheumatology (Oxford) 2004;43:1337-1345.

82 Eggert M, Kluter A, Zettl UK, Neeck G: Transcription factors in autoimmune diseases. Curr Pharm Des 2004;10:2787-2796.

83 Ivashkiv LB, Hu X: The JAK/STAT pathway in rheumatoid arthritis: pathogenic or protective? Arthritis Rheum 2003;48:20922096.
84 Korb A, Tohidast-Akrad M, Cetin E, Axmann R, Smolen J, Schett G: Differential tissue expression and activation of p38 MAPK alpha, beta, gamma, and delta isoforms in rheumatoid arthritis. Arthritis Rheum 2006; 54:2745-2756

85 Rottapel R: Putting the brakes on arthritis: can suppressors of cytokine signaling (SOCS) suppress rheumatoid arthritis? J Clin Invest 2001;108:1745-1747.

86 Aeberli D, Leech M, Morand EF: Macrophage migration inhibitory factor and glucocorticoid sensitivity. Rheumatology (Oxford) 2006;45:937-943.

87 Flaster H, Bernhagen J, Calandra T, Bucala $\mathrm{R}$ : The macrophage migration inhibitory factor-glucocorticoid dyad: regulation of inflammation and immunity. Mol Endocrinol 2007;21:1267-1280.

88 Zhou J, Cidlowski JA: The human glucocorticoid receptor: one gene, multiple proteins and diverse responses. Steroids 2005;70: 407-417

89 Lewis-Tuffin LJ, Cidlowski JA: The physiology of human glucocorticoid receptor beta (hGRbeta) and glucocorticoid resistance. Ann NY Acad Sci 2006;1069:1-9.

90 Webster JC, Oakley RH, Jewell CM, Cidlowski JA: Proinflammatory cytokines regulate human glucocorticoid receptor gene expression and lead to the accumulation of the dominant negative beta isoform: a mechanism for the generation of glucocorticoid resistance. Proc Natl Acad Sci USA 2001;98 6865-6870.

91 Li LB, Leung DY, Hall CF, Goleva E: Divergent expression and function of glucocorticoid receptor beta in human monocytes and T cells. J Leukoc Biol 2006;79:818-827.

92 Strickland I, Kisich K, Hauk PJ, Vottero A Chrousos GP, Klemm DJ, Leung DY: High constitutive glucocorticoid receptor beta in human neutrophils enables them to reduce their spontaneous rate of cell death in response to corticosteroids. J Exp Med 2001; 193:585-593.

93 Goleva E, Li LB, Eves PT, Strand MJ, Martin RJ, Leung DY: Increased glucocorticoid receptor beta alters steroid response in glucocorticoid-insensitive asthma. Am J Respir Crit Care Med 2006;173:607-616.
94 Sousa AR, Lane SJ, Cidlowski JA, Staynov DZ, Lee TH: Glucocorticoid resistance in asthma is associated with elevated in vivo expression of the glucocorticoid receptor beta-isoform. J Allergy Clin Immunol 2000;105:943-950.

95 Honda M, Orii F, Ayabe T, Imai S, Ashida T, Obara T, Kohgo Y: Expression of glucocorticoid receptor beta in lymphocytes of patients with glucocorticoid-resistant ulcerative colitis. Gastroenterology 2000; 118:859-866.

96 Towers R, Naftali T, Gabay G, Carlebach M, Klein A, Novis B: High levels of glucocorticoid receptors in patients with active Crohn's disease may predict steroid resistance. Clin Exp Immunol 2005;141:357362.

97 Kozaci DL, Chernajovsky Y, Chikanza IC: The differential expression of corticosteroid receptor isoforms in corticosteroid-resistant and -sensitive patients with rheumatoid arthritis. Rheumatology (Oxford) 2007;46:579-585.

98 Derijk RH, Schaaf MJ, Turner G, Datson NA, Vreugdenhil E, Cidlowski J, de Kloet ER, Emery P, Sternberg EM, Detera-Wadleigh SD: A human glucocorticoid receptor gene variant that increases the stability of the glucocorticoid receptor beta-isoform mRNA is associated with rheumatoid arthritis. J Rheumatol 2001;28:2383-2388.

99 Donn R, Payne D, Ray D: Glucocorticoid receptor gene polymorphisms and susceptibility to rheumatoid arthritis. Clin Endocrinol (Oxf) 2007;67:342-345.

100 Lee EB, Kim JY, Lee YJ, Song YW: Glucocorticoid receptor polymorphisms in Korean patients with rheumatoid arthritis. Ann Rheum Dis 2005;64:503-504.

101 DeRijk RH, Schaaf M, de Kloet ER: Glucocorticoid receptor variants: clinical implications. J Steroid Biochem Mol Biol 2002; 81:103-122.

102 van Rossum EF, Russcher H, Lamberts SW: Genetic polymorphisms and multifactorial diseases: facts and fallacies revealed by the glucocorticoid receptor gene. Trends Endocrinol Metab 2005;16:445-450.

103 Lu NZ, Cidlowski JA: Glucocorticoid receptor isoforms generate transcription specificity. Trends Cell Biol 2006;16:301307. 